\title{
The effects of methamphetamine and cocaine on motor behavior and extracellular dopamine in the ventral striatum of Lewis versus Fischer 344 rats
}

\author{
Dianne M. Camp, Kaitlin E. Browman, Terry E. Robinson \\ Department of Psychology and Neuroscience Program, The University of Michigan, Neuroscience Laboratory Building, 1103 East Huron Street, \\ Ann Arbor, MI 48104-1687, USA
}

Accepted 11 October 1994

\begin{abstract}
The effects of an acute systemic injection of methamphetamine (mAMP) or cocaine (COC) on motor behavior (stereotypy, locomotor activity, and rearing) and extracellular dopamine (DA) in the ventral striatum were compared in Lewis (LEW) versus Fischer 344 (F344) rats, using in vivo microdialysis in awake freely moving animals. In addition, the behavioral response to repeated mAMP injections (i.e. sensitization) was characterized in LEW and F344 rats, as was the possibility of strain differences in drug pharmacokinetics. The major findings were: (i) LEW rats showed greater behavioral activation to an acute injection of both MAMP and COC, as indicated by a shift to the left in the dose-effect curves relative to F344 rats. (ii) LEW rats were more susceptible to mAMP sensitization. (iii) An acute injection of mAMP or COC enhanced the extracellular concentration of DA to a greater extent in LEW rats, as indicated by a significant shift to the left in the dose-effect curve relative to F344 rats. (iv) Strain differences in the behavioral and neurochemical effects of these drugs were characterized largely by differences in the duration of the drug response. (v) LEW rats had higher plasma and brain levels of mAMP and COC than F344 rats, suggesting that strain differences in pharmacokinetics may contribute to strain differences in the behavioral and neurochemical effects of these drugs.
\end{abstract}

Keywords: Amphetamine; Microdialysis; Nucleus accumbens; Stimulants; Inbred rats strain; Locomotion; Stereotyped behavior; Sensitization; Pharmacokinetics

\section{Introduction}

Humans show considerable individual variation in their response to addictive drugs [42]. This is also true of nonhuman animals, as indicated, for example, by individual variation in the acquisition of drug self-administration behavior $[9,20,40]$. The factors responsible for this variability are no doubt complex, and involve genetic and environmental factors, and their interactions. One approach to investigating the role of genetic factors in drug addiction in animals is to study inbred strains of animals. Two inbred strains of rats that have received considerable attention recently, because they show marked differences in their behavioral response

\footnotetext{
Corresponding author. Fax: (1) (313) 936 2690. E-mail: dcamp@umich.edu.
}

to a variety of addictive drugs, are Lewis (LEW) and Fischer 344 (F344) rats. For example, LEW rats show a greater propensity to orally self-administer cocaine (COC), opiates and alcohol $[14,15,17,18,30,47,48,49]$, a greater locomotor response to systemic cocaine [17], and a greater conditioned place preference to systemic morphine and COC [22], compared to F344 rats. In addition, delta-9-tetrahydrocannabinol facilitates intracranial self-stimulation in LEW rats, but not in Sprague-Dawley, Long Evans or F344 rats [12,13]. These studies have led some researchers to suggest that LEW rats may have a generalized vulnerability to the rewarding effects of addictive drugs [16,37].

The neurobiological basis for these behavioral differences between LEW and F344 rats is not known. Since the rewarding properties of many addictive drugs are thought to be mediated, in part, by the mesolimbic dopamine (DA) system [52], strain differences in the 
behavioral responses to these drugs may be related to strain differences in DA neurotransmission. In support of this idea, Nestler and his colleagues have identified a number of regionally-specific biochemical differences in the nucleus accumbens and ventral tegmental area (VTA) between these two strains, including differences in levels of tyrosine hydroxylase, neurofilament proteins, adenylate cyclase, cyclic AMP-dependent protein kinase, G-proteins and glial fibrillary acidic protein $[2-4,22,23]$. On the other hand, there is no difference between LEW and F344 rats in striatal D1, D2 or mazindol binding [19], or in the expression, transcription and genomic organization of striatal D2 receptors [31], so it is not clear whether these strains differ in the effects of addictive drugs on DA neurotransmission. Since a common feature of many addictive drugs is their ability to increase the extracellular concentration of DA in the nucleus accumbens [10], we hypothesized that addictive drugs may affect DA neurotransmission differently in LEW and F344 rats by differentially elevating extracellular DA. Thus, the major purpose of the present study was to test this hypothesis. We did so by comparing the effects of an acute systemic injection of methamphetamine (mAMP) or COC on the extracellular concentration of DA in the nucleus accumbens in LEW and F344 rats, using in vivo microdialysis in awake freely moving animals. In addition, we characterized the behavioral response to repeated mAMP injections (i.e. sensitization) in LEW and F344 rats, and tested for strain differences in drug pharmacokinetics.

\section{Materials and methods}

\subsection{Experiment 1: The effects of mAMP or COC on motor behavior and extracellular dopamine in LEW and F344 rats}

\subsubsection{Subjects}

Subjects were male F344 and LEW rats (Harlan, Indianapolis, IN) of the same age (9-10 weeks) and weighing 180-240 g and $220-270 \mathrm{~g}$, respectively, at the beginning of the experiment. Animals were housed individually in wire-hanging cages in a light $(14: 10$ light:dark cycle, lights on at $06: 00 \mathrm{~h}$ ) and temperature $\left(68-74^{\circ} \mathrm{C}\right)$ controlled room with food and water continuously available. For the first experiment, which will be referred to as the mAMP experiment, each of the two strains was divided into two groups. One group received an injection of $0.5 \mathrm{mg} / \mathrm{kg}$ methamphetamine sulfate (mAMP) during the first dialysis test session and $2.0 \mathrm{mg} / \mathrm{kg}$ mAMP during a second test session, one week later. The second group received $1.0 \mathrm{mg} / \mathrm{kg}$ mAMP during the first test session and 4.0 $\mathrm{mg} / \mathrm{kg}$ mAMP during the second test session. In the second experiment, which will be referred to as the COC experiment, one group received an injection of $5.0 \mathrm{mg} / \mathrm{kg}$ cocaine- $\mathrm{HCl}(\mathrm{COC})$ during test session one and $15 \mathrm{mg} / \mathrm{kg} \mathrm{COC}$ during test session two. A second group received $10 \mathrm{mg} / \mathrm{kg}$ COC during test session one and $30 \mathrm{mg} / \mathrm{kg}$ $\mathrm{COC}$ during the second test session. Thus, in each experiment every rat was tested twice using two different doses of either mAMP or $\mathrm{COC}$ (with the smaller of the two doses always given during the first test session). Different hemispheres were used for the two dialysis test sessions, and right and left sides were randomized across test sessions. During a given test session equal or nearly equal numbers of F344 and LEW rats were tested (typically 5 LEW and 5 F344 rats were tested together), and rats were randomized across the different test chambers. All drug doses are expressed as the weight of the salt, and drugs were dissolved in $1.0 \mathrm{mg} / \mathrm{ml}$ of $0.9 \%$ saline and administered intraperitoneally. Finally, the mAMP experiment was completed prior to the start of the COC experiment.

\subsubsection{Surgical procedures}

Following one week of habituation to the animal room and to being handled, animals were pretreated with atropine methyl nitrate ( $5 \mathrm{mg} / \mathrm{kg}$, i.p.), anesthetized with sodium pentobarbital (30-50 $\mathrm{mg} / \mathrm{kg}$, i.p.), supplemented with methoxyflurane as necessary, and using standard stereotaxic procedures 21-gauge stainless steel guide cannulae were placed on the dural surface above each nucleus accumbens and fixed in place with dental cement and jeweler's screws attached to the skull. The coordinates were: (for F344 rats) anterior to bregma, $1.2-1.8 \mathrm{~mm}$; lateral, $1.1-1.6 \mathrm{~mm}$; and ventral, 1.0 $\mathrm{mm}$ from the skull surface; (for LEW rats) anterior, 2.4-2.7 mm; lateral, 1.4-1.6 mm; and ventral, $1.0 \mathrm{~mm}$ [39]. In addition, a 10-12 $\mathrm{mm}$ piece of 17 -gauge stainless steel tubing with a $90^{\circ}$ bend at the lower end was positioned in the dental cement about $5 \mathrm{~mm}$ posterior to the guide cannulae to be later used to attach the animal to a tether.

After implantation of the guide cannulae all rats were castrated. This was done because circulating testicular hormones are known to influence the behavioral response to psychomotor stimulant drugs $[1,7]$, in part because of their effect on drug metabolism [27], and we wanted to eliminate the possibility that pharmacokinetic factors due to strain differences in circulating levels of gonadal hormones would influence the results.

\subsubsection{Microdialysis procedures}

One week following surgery rats were lightly anesthetized using ether and methoxyflurane, and a single microdialysis probe was lowered into either the right or left nucleus accumbens via a guide cannula. The concentric-shaped dialysis probe was basically as described by Robinson and Camp [41], with a few modifications. Both the inlet and outlet lines consisted of fused silica, and the length of dialysis membrane ( $250 \mu \mathrm{m}$ O.D.) extended from the bottom of the guide cannula to the ventral tip of the probe. The dialysis membrane was coated with cyanoacrylate glue (Cyanodent Fast, Ellman International, Hewlett, NY), except for the most ventral $2 \mathrm{~mm}$ at its tip (i.e. the dialysis surface was $2 \mathrm{~mm}$ long). After the probe was lowered into the nucleus accumbens, the animal was placed into a $46 \times 27 \times$ $28.5 \mathrm{~cm}$ oval-shaped Plexiglas chamber. The animal was connected to a liquid swivel (Instech) via a steel tether (model airplane cable) fastened to the piece of stainless steel tubing that protuded from the back of the dental cement 'cap' on the animal's head. The animals were then left undisturbed overnight, and food and water were freely available in the dialysis chambers. The perfusion solution consisted of $145 \mathrm{mM} \mathrm{NaCl}, 2.7 \mathrm{mM} \mathrm{KCl}, 1.2 \mathrm{mM} \mathrm{CaCl}_{2}, 1.0 \mathrm{mM} \mathrm{MgCl}$ and $0.2 \mathrm{mM}$ ascorbic acid, $\mathrm{pH} 7.3$ [35], and it was pumped through the probe overnight at $0.3 \mu \mathrm{l} / \mathrm{min}$.

The next morning the first test session commenced. The pump was turned up to $1.5 \mu \mathrm{l} / \mathrm{min}$ and after a $1.5-2 \mathrm{~h}$ equilibration period three $20 \mathrm{~min}$ 'baseline' samples of dialysate were collected. Following collection of baseline samples, the animals received $1 \mathrm{ml} / \mathrm{kg}$ of $0.9 \%$ saline, and three $20 \mathrm{~min}$ 'saline' samples were collected. Immediately following collection of the last saline sample all animals received an injection of $\mathrm{mAMP}$ or $\mathrm{COC}$, and eight additional $20 \mathrm{~min}$ samples were collected. After the last of these samples had been collected the dialysis probe was removed, the stylet replaced, and the animals were returned to their home cage. A second test session was conducted one week later using the same procedures as described 
above, and the same animals, but a dialysis probe was placed in the contralateral nucleus accumbens. Dialysate samples were assayed for DA, DOPAC, 5-HIAA and HVA by HPLC with electrochemical detection using procedures similar to those described previously [41].

\subsubsection{Measurement of motor behavior}

Response to a novel environment. Prior to the first dialysis test session all rats were placed into the test chambers described above, and two measures of motor behavior were acquired over $5 \mathrm{~min}$ intervals for $1 \mathrm{~h}$. Movement from one side of the long axis of the cage to the other (crossovers) was detected using two photocells placed $23.5 \mathrm{~cm}$ apart and $4.5 \mathrm{~cm}$ above the cage floor. A single count was registered when the animal crossed the photocell beam, and another count from that photocell could not be registered until the other photocell beam was broken. An estimate of rearing behavior was obtained using four photocells positioned near the four corners of the chambers and $13.5 \mathrm{~cm}$ above the cage floor.

mAMP and COC tests. Crossovers and rearing were also recorded, as described above, for $60 \mathrm{~min}$ following an injection of saline and for $160 \mathrm{~min}$ following the administration of mAMP or COC. In addition, following drug administration every animal was videotaped, and the videotapes later were used to visually rate drug-induced behavior using a 9-point scale adapted from Ellinwood and Balster [11]. On this scale, $1=$ asleep; $2=$ inactive; $3=$ normal in place activity; $4=$ normal, alert, active; $5=$ hyperactive; $6=$ slow patterned stereotyped behavior; $7=$ fast patterned stereotyped behavior; $8=$ restricted stereotyped behavior; and $9=$ dyskinetic-reactive behavior. Behavior was rated during a $30 \mathrm{~s}$ period every $10 \mathrm{~min}$ following the mAMP or COC injection for $160 \mathrm{~min}$ by a person blind to the experimental condition. In addition, the number of rears (defined as both forepaws elevated) occurring during each of these $30 \mathrm{~s}$ periods was also recorded and used to validate the automated measurement of rearing. The correlation between the automated and visual measurements of rearing was $r=0.89$.

\subsubsection{Sensitization}

A separate behavioral experiment using independent groups of animals (i.e. they were not used in the dialysis experiments) was conducted to determine whether repeated intermittent treatment with mAMP produced comparable behavioral sensitization in LEW and F344 rats. For this experiment castrated male rats were placed into the test chambers described above, and after a $1 \mathrm{~h}$ habituation period they received an injection of either saline or $2.0 \mathrm{mg} / \mathrm{kg}$ of mAMP ( $n=9-10 /$ group), and behavior recorded (as described above) for an additional $160 \mathrm{~min}$. This procedure was repeated every 3-4 days for a total of 5 injections. During a final sixth test session, 3-4 days after the fifth, all animals (both saline and mAMP pretreated) received $2.0 \mathrm{mg} / \mathrm{kg}$ of mAMP.

\subsubsection{Histological verification of probe placement}

Upon completion of the second dialysis test session each animal was perfused through the heart with $0.9 \%$ saline followed by $10 \%$ formalin in saline, its brain removed, and stored in $10 \%$ formalin in saline. The brains were sectioned and stained with Cresyl violet, and examined to determine the exact location of each dialysis probe.

\subsubsection{Data analyses}

The behavioral rating scores were analyzed using nonparametric statistics, including Profile analyses [36] and, if significant, subsequent Mann-Whitney $U$-tests. Crossovers, rearing, and the neurochemical data were analyzed using parametric statistics, including one- or two-way analyses of variance and, if significant, subsequent Fisher's PLSD post hoc tests or Student's t tests for planned comparisons. Because of equipment malfunctions (e.g. microcomputer, videorecorders, or chromatography) group $n$ values for the behavioral and neurochemical measurements sometimes differed. For example, in the COC experiment $2 \mathrm{LEW}$ and 7 F344 rats were excluded from the analyses of the effect of COC on DA because of chromatography problems. For simplicity, the final group $n$ values for each statistical analysis are listed in the figure legends along with the summaries of the statistical tests. Finally, data for the MAMP- and COC-treated animals were analyzed separately because these groups were tested at different points in time, approximately one year apart.

In vitro recovery was performed on all dialysis probes prior to each use, and dialysate values reported here were corrected for recovery. The average ( \pm S.E.M.) recovery values for probes used in the mAMP experiment were: DA, $14.48 \pm 0.65 \%$ and $14.45 \pm 0.73 \%$ for LEW $(n=37)$ and F344 $(n=31)$ rats, respectively; DOPAC, $12.06 \pm 0.58 \%$ and $12.42 \pm 0.63 \%$; HVA, $11.39 \pm 0.52 \%$ and $11.61 \pm$ $0.58 \%$; 5 -HIAA, $12.39 \pm 0.58 \%$ and $12.56 \pm 0.63 \%$. The recovery values did not differ significantly between strains. For the COC experiment recovery values were: $\mathrm{DA}, 16.13 \pm 0.35 \%$ and $14.92 \pm 0.38 \%$ $(n=49$ and 57); DOPAC, $13.80 \pm 0.31$ and $12.68 \pm 0.38$; HVA, 13.36 \pm 0.29 and $12.24 \pm 0.34 ; 5$-HIAA, $14.52 \pm 0.36$ and $13.27 \pm 0.37$. The recovery values were significantly higher for LEW rats, compared to F344 rats $(P<0.05)$.

\subsection{Experiment 2: MAMP and COC pharmacokinetics}

Male LEW and F344 rats were obtained and housed as described in Experiment 1. After one week, all rats were castrated under general anesthesia (as described above). One week later each rat was given a single i.p. injection of either $2.0 \mathrm{mg} / \mathrm{kg} \mathrm{mAMP}$ (weight of the salt) or $10 \mathrm{mg} / \mathrm{kg} \mathrm{COC} \mathrm{(weight} \mathrm{of} \mathrm{the} \mathrm{salt),} \mathrm{and} \mathrm{returned} \mathrm{to} \mathrm{its} \mathrm{home}$ cage. At 40,80 (COC animals only) or 120 (mAMP animals only) min later, animals were decapitated, and trunk blood and brains were obtained for determination of mAMP, amphetamine or COC concentrations. Blood was immediately centrifuged at $3,000-5,000 \mathrm{rpm}$ for $10 \mathrm{~min}$ at $4^{\circ} \mathrm{C}$, and one $\mathrm{ml}$ of plasma was transferred to a test tube and immediately frozen at $-20^{\circ} \mathrm{C}$. The brain was rinsed with ice cold saline, and then placed into a chilled cutting block. A $3 \mathrm{~mm}$ coronal slice corresponding to sections 2 and 3 , as described by Heffner et al. [24], was used to generate the brain tissue sample. The tissue was weighed and then homogenized in $1 \mathrm{ml}$ of ice cold HPLC-grade water. These samples were immediately frozen at $-20^{\circ} \mathrm{C}$ until assayed. Standards were prepared by adding known amounts of drug to the plasma or brain homogenates from noninjected animals. It should be noted that the blood and brain samples to be assayed for COC levels were prepared in $1 \%$ sodium fluoride to inhibit cocaine degradation [5]. Determination of drug concentrations in these samples was performed by the Center for Human Toxicology, University of Utah, using gas chromatography coupled to positive ion chemical ionization mass spectrometry, with quantitation in the selected ion monitoring mode.

\section{Results}

\subsection{Behavior}

\subsubsection{Response to a novel environment}

Fig. 1 shows the time course of motor activity (crossovers and rearing) following placement in a novel environment in LEW and F344 rats tested in the COC experiment. Although the differences were small, LEW rats showed significantly more motor activity in response to a novel environment than F344 rats (see figure captions for summaries of the statistical analyses). The same effect was found in the mAMP experiment (data not shown). 


\subsubsection{Dose-effect curves for $M A M P$ and $C O C$}

Strain differences in the psychomotor activating effects of mAMP and COC were assessed using three different behavioral measures - a visual rating scale, crossovers and rearing. COC did not produce focussed, in place, stereotyped behavior (i.e. a rating score of 8) at any of the four doses tested, and therefore, ratings were not analyzed for the COC-treated animals. Fig. 2 shows the mAMP dose-effect curves for LEW and F344 rats based on the behavioral rating scores. LEW rats showed significantly greater behavioral activation to mAMP than F344 rats, as indicated by a significant shift to the left in their dose-effect curve. Further analyses of the time course of the rating scores at each dose, shown in Fig. 3, indicated that the strain difference was due primarily to a longer duration of action of mAMP in LEW rats, rather than to a difference in the peak effect of the drug (except at the $2.0 \mathrm{mg} / \mathrm{kg}$ dose, which produced a greater peak effect in LEW rats).

Strain differences in the dose-effect curves for mAMP and COC-induced locomotor activity (crossovers) are shown in panels I (insert) in Figs. 4 and 5. Locomotor activity increased with higher doses, except at the highest dose of mAMP tested. At $4.0 \mathrm{mg} / \mathrm{kg}$ of mAMP locomotor activity decreased relative to that

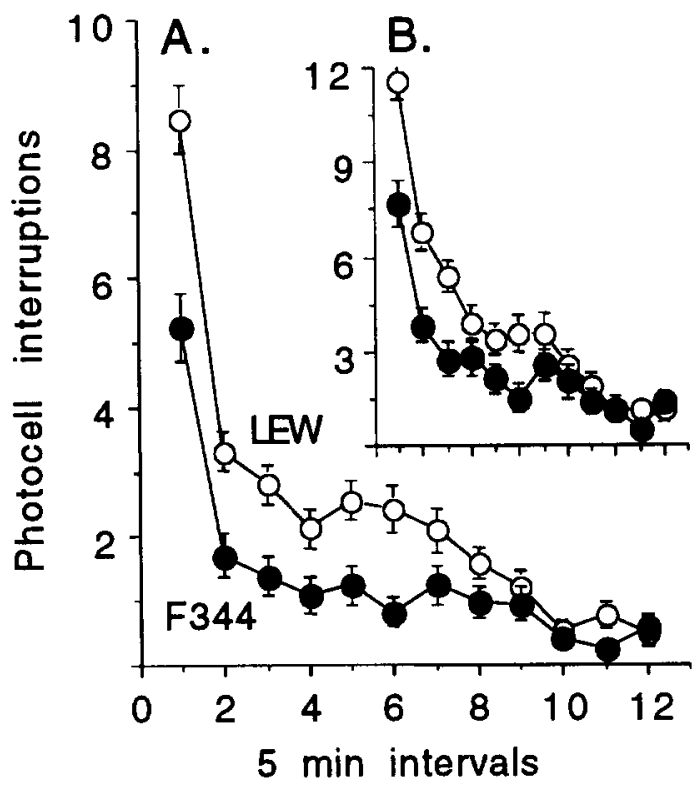

Fig. 1. Crossovers from one side of the test chamber to the other (locomotor activity; Panel A) and the incidence of rearing behavior (Panel B, insert) of LEW (open circles) and F344 (closed circles) rats in response to a novel environment. Values represent means \pm S.E.M. LEW rats showed significantly greater spontaneous motor activity than F344 rats (two-way ANOVA's with repeated measures on one factor). Crossovers - effect of strain, $F=25.7, P<0.0001$; effect of time, $F=78.5, P<0.0001$; strain $\times$ time interaction, $F=5.47, P<$ 0.0001 ; Rears - effect of strain, $F=20.07, P<0.0001$; effect of time $F=54.3, P<0.0001$; strain $\times$ time interaction, $F=3.86, P<0.0001$. Group $n$ values: LEW, $n=48$; F344, $n=51$.

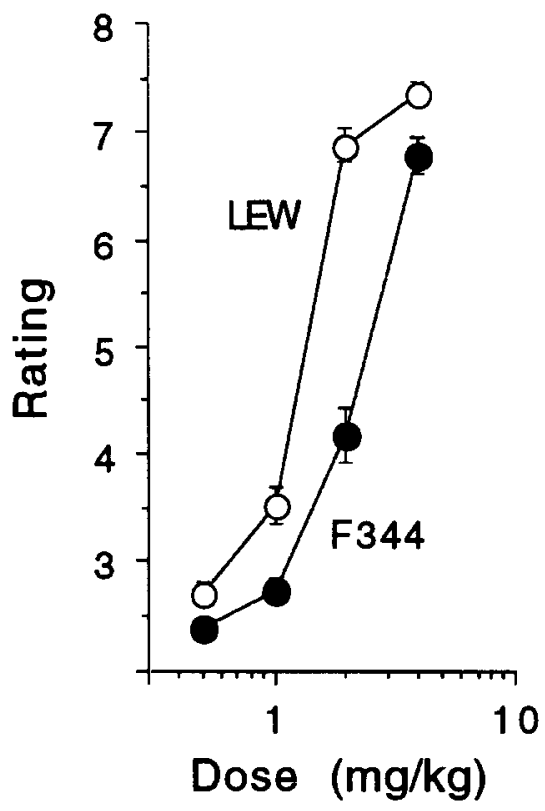

Fig. 2. The mean ( \pm S.E.M.) behavioral rating scores averaged over $160 \mathrm{~min}$ following an injection of $0.5,1.0,2.0$ or $4.0 \mathrm{mg} / \mathrm{kg}$ of mAMP. LEW rats (open circles) showed a significant shift to the left in the dose-effect curve, compared to F344 rats (closed circles). Mann-Whitney $U$-tests were performed comparing LEW and F344 rats at each dose: $0.5 \mathrm{mg} / \mathrm{kg}, U=63, P=0.04 ; 1.0 \mathrm{mg} / \mathrm{kg}, U=27.5$, $P=0.0007 ; 2.0 \mathrm{mg} / \mathrm{kg}, U=0, P<0.0001 ; 4.0 \mathrm{mg} / \mathrm{kg}, U=16.5$, $P=0.015$. Group $n$ values: $0.5 \mathrm{mg} / \mathrm{kg}$, LEW $n=15$, F344 $n=15 ; 1.0$ $\mathrm{mg} / \mathrm{kg}$, LEW $n=15$, F344 $n=14 ; 2.0 \mathrm{mg} / \mathrm{kg}$, LEW $n=13$, F344 $n=12 ; 4.0 \mathrm{mg} / \mathrm{kg}$, LEW $n=12$, F344 $n=8$.

seen following $2.0 \mathrm{mg} / \mathrm{kg}$ mAMP. This decrease occurred because animals were engaged in stereotyped behavior (as described above; also see Fig. 3). Although there was no significant strain difference in the mAMP dose-effect curves, the time course of mAMPinduced locomotor activity at each dose, shown in panels A, C, E and G in Fig. 4, clearly showed that the pattern of locomotor activity differed between the two strains. LEW rats showed a more sustained increase in locomotor activity than F344 rats at the two lower doses of mAMP, and at the $4.0 \mathrm{mg} / \mathrm{kg}$ dose of mAMP showed a more sustained stereotypy phase than F344 rats, as indicated by the absence of any locomotor activity at the end of the test session. LEW rats also showed a more sustained increase in COC-induced locomotor activity, but only following $10 \mathrm{mg} / \mathrm{kg}$ and 30 $\mathrm{mg} / \mathrm{kg}$ of COC (see panels A, C, E, G and I in Fig. 5). The pattern of strain differences for mAMP- and COC-induced rearing was similar to that described above for crossovers. As shown in panels B, D, F, and $\mathrm{H}$ of Figs. 4 and 5, LEW rats generally exhibited a longer duration of enhanced rearing following an injection of mAMP or COC than F344 rats. At a mAMP dose of $4.0 \mathrm{mg} / \mathrm{kg}$ LEW rats exhibited less rearing than F344 rats, and this was due to LEW rats engaging in focussed, in place, stereotypy. 


\subsubsection{Sensitization}

Fig. 6 shows behavioral activity ratings for LEW and F344 rats following each of five successive injections of mAMP, and then also after a sixth injection, when both saline- and mAMP-pretreated animals received a mAMP 'challenge'. Fig. 6 shows that mAMP produced a greater behavioral effect in LEW rats, relative to F344 rats, even during the first test session, consistent with the dose-effect analysis described above. In addition, both LEW and F344 rats showed a significant increase in ratings between the first and fifth test sessions, and in both strains mAMP-pretreated animals had significantly higher ratings than saline-pretreated animals on the 'challenge' test day. Thus, both strains showed sensitization to the behavioral activating effects of mAMP.

Sensitization was also evident upon examination of the automated measure of locomotor activity ('crossovers'), although the pattern of change was quite different in LEW and F344 rats (data not shown). The F344 rats showed primarily locomotor hyperactivity (without stereotyped sniffing and head movements) during the first test session, and even greater locomotor hyperactivity by the sixth test session (but still not much stereotyped behavior). In contrast, during the first test session LEW rats showed comparable locomotor hyperactivity to F344 rats (there was no strain

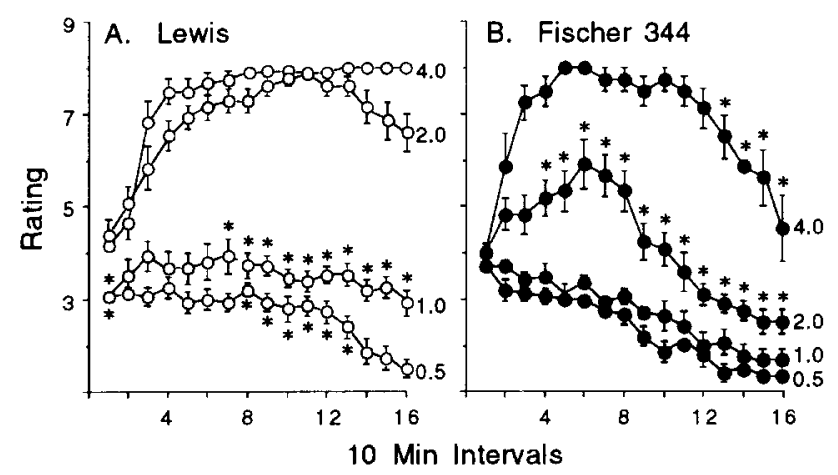

Fig. 3. The mean ( \pm S.E.M.) behavioral rating scores during each ten minute interval for $160 \mathrm{~min}$ following an injection of $0.5,1.0,2.0$ or $4.0 \mathrm{mg} / \mathrm{kg}$ of mAMP in LEW (left panel) and F344 (right panel) rats. Profile analyses were performed comparing LEW and F344 rats at each dose: $0.5 \mathrm{mg} / \mathrm{kg}$, effect of strain, $F=5.87, P=0.022$, effect of time, $F=8.66, P<0.0001$, parallelism, $F=2.27, P=0.066 ; 1.0$ $\mathrm{mg} / \mathrm{kg}$, effect of strain, $F=16.29, P=0.0004$, effect of time, $F=$ 2.69, $P=0.04$, parallelism, $F=2.66, P=0.04 ; 2.0 \mathrm{mg} / \mathrm{kg}$, effect of strain, $F=79.3, P<0.0001$, effect of time, $F=3.55, P=0.038$, parallelism, $F=3.07, P=0.057 ; 4.0 \mathrm{mg} / \mathrm{kg}$, a Profile analysis could not be performed because there was no variability for some of the intervals in LEW rats (i.e. all LEW rats had a behavioral rating score of 8 during the last four $10 \mathrm{~min}$ intervals, whereas only 1-3 F344 rats had a score of 8 during this same time period). Group $n$ values are the same as in Fig. 2. Subsequent Mann-Whitney $U$-tests at each 10 min interval were performed to determine at which times LEW and F344 rats differed $(P<0.05)$, and these times are indicated by the asterisks. difference in the number of 'crossovers'), although in LEW rats this was accompanied by stereotyped sniffing and head movements. By the sixth test session LEW animals made very few crossovers because they were engaged primarily in focussed stereotyped behavior (Fig. 6). Thus, with this dose of mAMP, sensitization in F344 rats was characterized by a shift from locomotor hyperactivity to greater locomotor hyperactivity, whereas in LEW rats sensitization was characterized by a shift from locomotor hyperactivity (with stereotyped sniffing and head movements) to focussed, in place, stereotyped behavior.

It is very difficult, however, to directly compare the rate of sensitization in LEW vs. F344 rats using the data presented in Fig. 6, because the two groups differed so much on the first test day, and because of the nature of ordinal scales. In an attempt to control for this variable the LEW and F344 groups were divided into two subgroups that did not differ in their acute response to mAMP. This was done by dividing the groups into those above (high) or below (low) the median on the first test session. The smaller symbols connected with dashed lines plotted in Fig. 6 show that there was no difference between LEW (low) and F344 (high) subgroups on the first test session, but a marked difference by the fifth test session, consistent with the conclusion that LEW animals showed greater sensitiztion than F344 animals, even after controlling for strain differences in acute drug response.

\subsection{Dialysis}

\subsubsection{Dialysis probe placements}

Fig. 7 shows the location of the dialysis surface of probes in the ventral striatum for all mAMP- and COC-treated animals for which neurochemical data were used. Animals with unacceptable probe placements were excluded from the neurochemical analyses, and their placements are not shown. As can be seen, there was considerable variability in probe placements within the ventral striatum. Some probes extended dorsally into the caudate nucleus and others ventrally into the olfactory tubercle, but most were centered in the region of the nucleus accumbens. Most importantly, however, there was considerable overlap in placements between LEW and F344 rats. To determine whether there was a statistical difference in the locations of probe placements between F344 and LEW rats, the ventral striatum was subdivided into three equal regions along each of the following planes: anterior-posterior (A-P), medial-lateral (M-L) and dorsalventral (D-V), and chi-square analyses were performed on the number of rats in each strain with placements in each of these three regions. There was no significant strain difference in probe placements in any dimension, except in one case. In the COC experiment, there 
were significantly more LEW rats with relatively ventral placements $(34.0 \%$ vs. $8.0 \%)$, and more F344 rats with dorsal $(22.0 \%$ vs. $10.6 \%)$ and middle $(70.0 \%$ vs. $55.3 \%$ ) placements ( $\chi^{2}$ statistic $=8.78, P=0.012$ ).

\subsubsection{Basal extracellular concentrations of $D A$ and metabolites}

The mean basal extracellular concentrations of DA, DOPAC, HVA and 5-HIAA in LEW and F344 rats are shown in Fig. 8, with mAMP-treated animals represented in Panel A and COC-treated animals in Panel B. Consistent with Strecker et al. [46], the basal extracellular concentration of DA was slightly lower in LEW rats compared to F344 rats, but this difference was not statistically significant in either the mAMP- or COC-treated animals. In contrast, the DA metabolites,
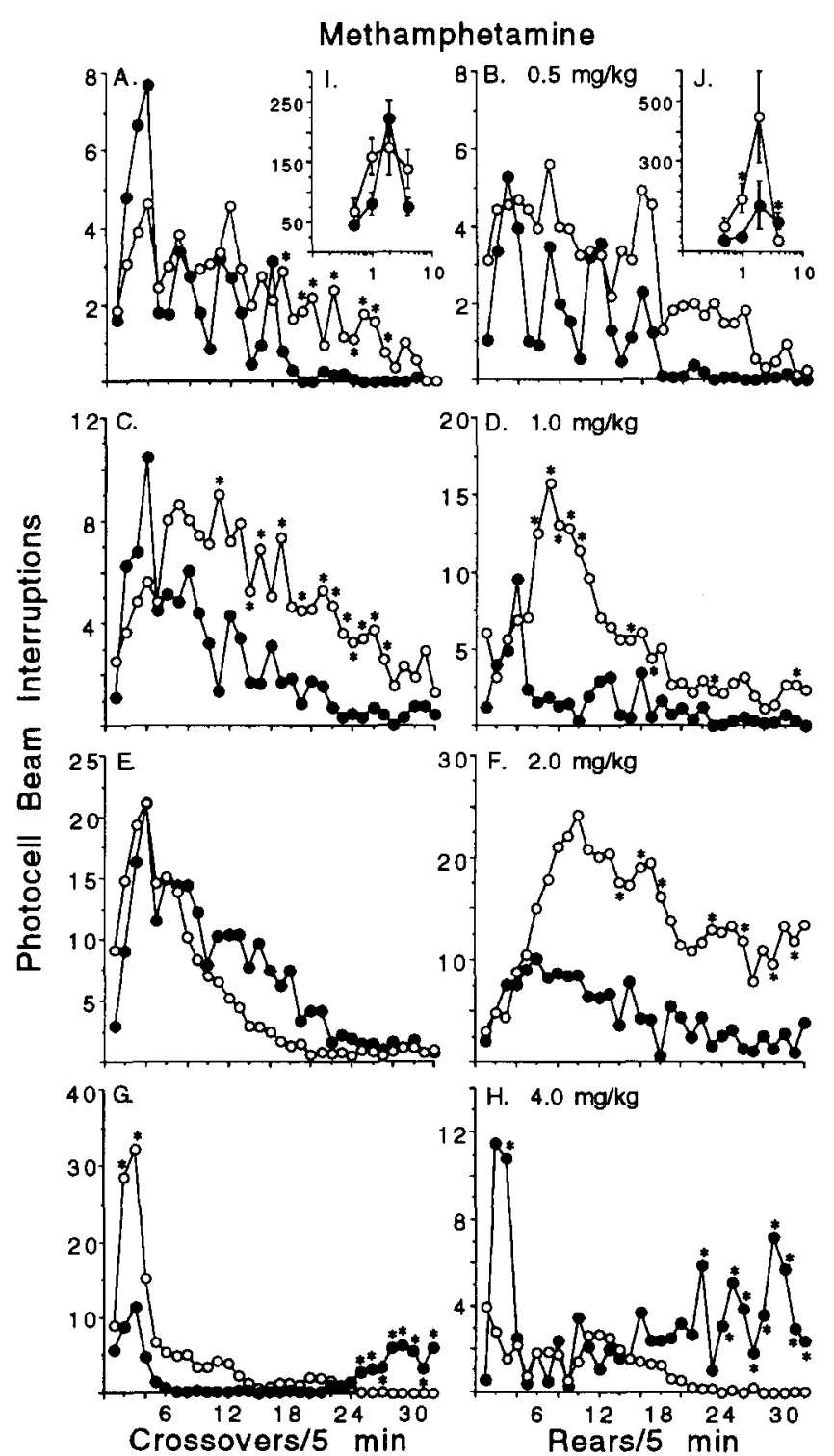

DOPAC and HVA, were significantly lower in LEW rats. (For COC animals, both DOPAC and HVA were significantly lower in LEW rats, but for mAMP animals the difference was statistically significant only for HVA.) In contrast to the DA metabolites, the extracellular concentration of the serotonin metabolite, 5HIAA, did not significantly differ between the two strains.

\subsubsection{Dose-effect for $M A M P$ and $C O C$}

Fig. 9 shows the extracellular concentration of DA, expressed as a percent of baseline, averaged over the entire $160 \mathrm{~min}$ collection period following an injection of mAMP (panel A) or COC (panel B) in LEW and F344 rats. Both drugs produced a dose-dependent increase in the extracellular concentration of DA, but this increase was significantly greater in LEW rats relative to $\mathrm{F} 344$ rats, as indicated by a significant shift to the left in the dose-effect curve for LEW rats. Further analyses of the time course of mAMP-stimulated DA release at each dose showed that the greater

Fig. 4. The mean number of crossovers (panels A, C, E, and G) and rears (panels $B, D, F$, and $H$ ) per five min interval for $160 \mathrm{~min}$ following an injection of $0.5,1.0,2.0$ or $4.0 \mathrm{mg} / \mathrm{kg}$ of mAMP in LEW (open circles) and F344 (closed circles) rats. Two-way ANOVA's with one repeated measure showed a significant effect of time at each dose ( $F$ 's range from 3.6-17.1, all $P$ 's $<0.0001$; except rears at 4.0 $\mathrm{mg} / \mathrm{kg}, F=1.57, P=0.026)$. There were significant strain differences at some doses, but not others. Analyses of Crossovers: 0.5 $\mathrm{mg} / \mathrm{kg}$, effect of strain, $F=1.08, P=0.31$, strain $\times$ time interaction, $F=1.87, P=0.003 ; 1.0 \mathrm{mg} / \mathrm{kg}$, effect of strain, $F=4.13, P=0.051$, strain $\times$ time interaction, $F=2.31, P<0.0001 ; 2.0 \mathrm{mg} / \mathrm{kg}$, effect of strain, $F=0.78, P=0.38$, strain $\times$ time interaction, $F=1.36, P=$ $0.093 ; 4.0 \mathrm{mg} / \mathrm{kg}$, effect of strain, $F=2.34, P=0.139$, strain $\times$ time interaction, $F=3.94, P<0.0001$. Analyses of Rears: $0.5 \mathrm{mg} / \mathrm{kg}$, effect of strain, $F=3.02, P=0.09$, strain $\times$ time interaction, $F=0.79$, $P=0.79 ; 1.0 \mathrm{mg} / \mathrm{kg}$, effect of strain, $F=5.32, P=0.028$, strain $\times$ time interaction, $F=2.38, P<0.0001 ; 2.0 \mathrm{mg} / \mathrm{kg}$, effect of strain, $F=3.02, P=0.094$, strain $\times$ time interaction, $F=1.80, P=0.005$; $4.0 \mathrm{mg} / \mathrm{kg}$, effect of strain, $F=4.46, P=0.045$, strain $\times$ time interaction, $F=2.39, P<0.0001$. When the overall ANOVA showed a significant interaction effect, subsequent unpaired Student's $t$-tests (two-tailed) at each point in time after mAMP were performed to determine at which times the groups differed $(P<0.05)$, and these times are indicated by the asterisks. Panel inserts (dose-effect curves): the mean ( \pm S.E.M.) number of crossovers (panel I) and rears (panel J) recorded by the microcomputer and cumulated over the $160 \mathrm{~min}$ following an injection of $0.5,1.0,2.0$ or $4.0 \mathrm{mg} / \mathrm{kg}$ of mAMP. A two-way ANOVA performed on the crossover data showed a significant effect of dose $(F=9.2, P<0.0001)$, but no significant effects of strain $(F=2.15, P=0.14)$, or dose $\times$ strain interaction $(F=2.03$, $P=0.11$ ). A two-way ANOVA performed on the rearing data showed significant effects of strain $(F=5.39, P=0.02)$, dose $(F=6.5, P=$ $0.0004)$ and strain $\times$ dose interaction $(F=2.79, P=0.04)$. The asterisks indicate that LEW rats showed greater rearing at $1.0 \mathrm{mg} / \mathrm{kg}$ of mAMP, and less rearing at $4.0 \mathrm{mg} / \mathrm{kg}$ of mAMP, relative to $\mathrm{F} 344$ rats (unpaired Student's $t$-tests, $P<0.05$ ). Group $n$ values: 0.5 $\mathrm{mg} / \mathrm{kg}$, LEW $n=16$, F344 $n=20 ; 1.0 \mathrm{mg} / \mathrm{kg}$, LEW $n=18$, F344 $n=14 ; 2.0 \mathrm{mg} / \mathrm{kg}$, LEW $n=14$, F344 $n=14 ; 4.0 \mathrm{mg} / \mathrm{kg}$, LEW $n=16$, F344 $n=10$. 
response observed in LEW rats, relative to F344 rats, was due largely to LEW rats displaying a more prolonged elevation in extracellular DA (see Fig. 10). Although analyses of the time course of the effect of COC on extracellular DA at each dose were highly significant for the effect of time, only the $10 \mathrm{mg} / \mathrm{kg}$ dose of $\mathrm{COC}$ resulted in a significant strain difference (LEW > F344; see Fig. 11).

The extracellular concentrations of DOPAC, HVA and 5-HIAA following $\mathrm{MAMP}$ and $\mathrm{COC}$ were also determined (data not shown). As expected, mAMP decreased DOPAC and HVA concentrations at all doses tested. In addition, there were significant strain differences in the effect of mAMP on both DA metabolites, when the data were expressed as a percent of the basal values. DOPAC and HVA declined to a greater extent in LEW rats compared to F344 rats. At the two lower doses, the magnitude as well as the

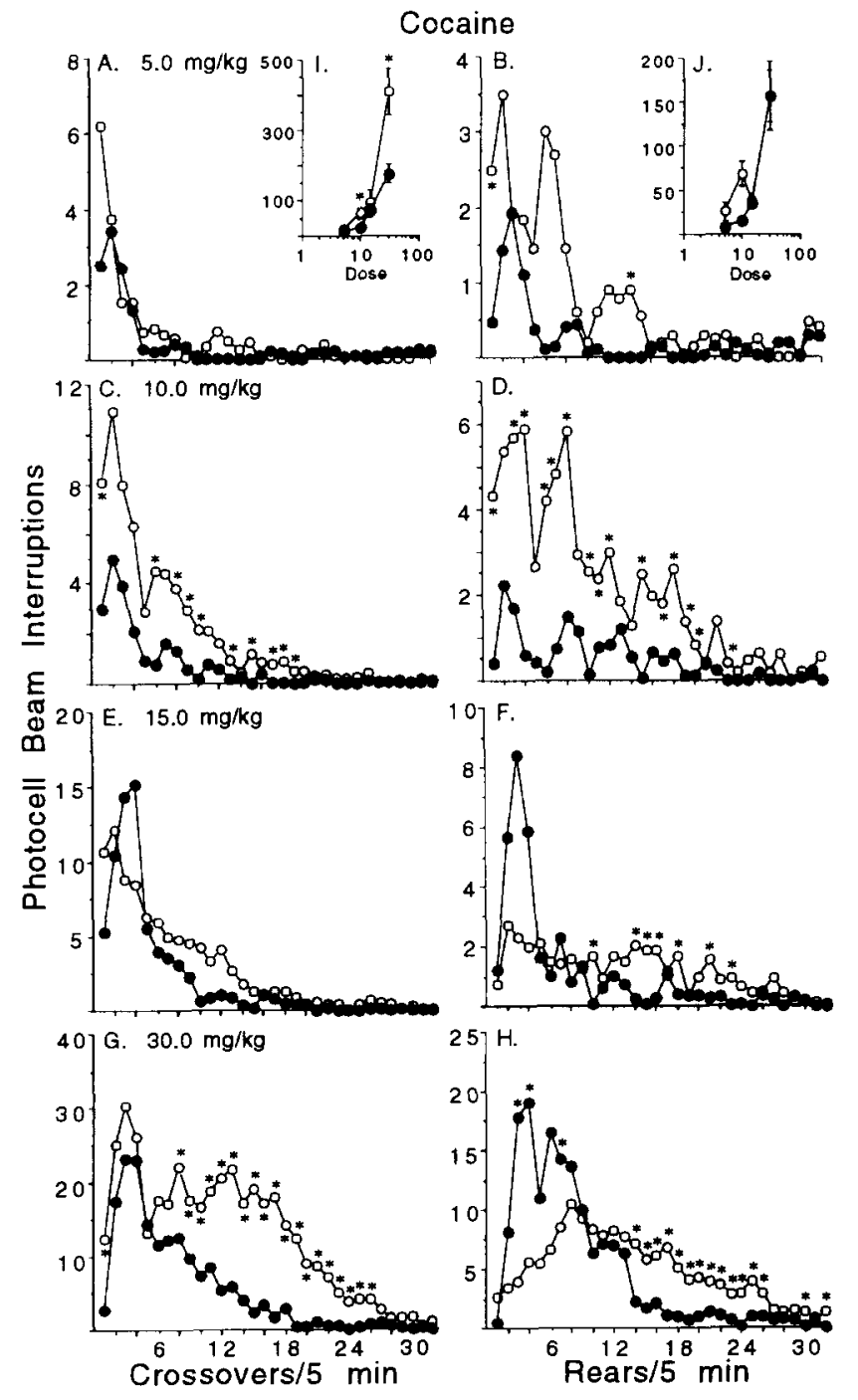

duration of the decline was greater in LEW rats. At the two higher doses, the magnitude of the decline was similar between the strains, probably due to a floor effect, but the duration of the decline was still greater in LEW rats. In contrast, mAMP produced a small increase ( $\sim 115 \%$ of basal) in the extracellular concentration of 5-HIAA which was significantly greater in F344 rats compared to LEW rats following mAMP doses of $0.5,1.0$ and $2.0 \mathrm{mg} / \mathrm{kg}$, but not $4.0 \mathrm{mg} / \mathrm{kg}$. The extracellular concentrations of DOPAC, HVA and 5-HIAA following COC were also determined (data not shown). Consistent with previous reports [25,26,38], COC had very little effect on the DA metabolite levels, relative to the changes seen following mAMP. For example, DOPAC concentrations decreased to about $75-85 \%$ of baseline values, and HVA decreased to an even lesser extent. Furthermore, these effects were not dose-dependent. 5-HIAA concentrations showed no change or a slight increase following COC. Following $\mathrm{COC}$ there were no consistent strain differences in any of the three metabolites measured.

Fig. 5. The mean number of crossovers (panels A, C, E, and G) and rears (panels $\mathrm{B}, \mathrm{D}, \mathrm{F}$, and $\mathrm{H}$ ) per five min interval for $160 \mathrm{~min}$ following an injection of $5,10,15$ or $30 \mathrm{mg} / \mathrm{kg}$ of cocaine in LEW (open circles) and F344 (closed circles) rats. Two-way ANOVA's with one repeated measure showed a significant effect of time at each dose ( $F$ 's range from $3.5-26.9$, all $P$ 's $<0.0001$ ). There were significant strain differences at some doses, but not others. Analyses of Crossovers: $5 \mathrm{mg} / \mathrm{kg}$, effect of strain, $F=1.32, P=0.26$, strain $\times$ time interaction, $F=1.37, P=0.086 ; 10 \mathrm{mg} / \mathrm{kg}$, effect of strain, $F=7.30$, $P=0.009$, strain $\times$ time interaction, $F=2.88, P<0.0001 ; 15 \mathrm{mg} / \mathrm{kg}$, effect of strain, $F=0.17, P=0.68$, strain $\times$ time interaction, $F=1.40$, $P=0.073 ; 30 \mathrm{mg} / \mathrm{kg}$, effect of strain, $F=10.8, P=0.002$, strain $\times$ time interaction, $F=3.35, P<0.0001$. Analyses of Rears: $5 \mathrm{mg} / \mathrm{kg}$, effect of strain, $F=3.74, P=0.059$, strain $\times$ time interaction, $F=$ $1.51, P=0.037 ; 10 \mathrm{mg} / \mathrm{kg}$, effect of strain, $F=15.5, P=0.0002$, strain $\times$ time interaction, $F=3.41, P<0.0001 ; 15 \mathrm{mg} / \mathrm{kg}$, effect of strain, $F=0.08, P=0.78$, strain $\times$ time interaction, $F=2.64, P<$ $0.0001 ; 30 \mathrm{mg} / \mathrm{kg}$, effect of strain, $F=0.00, P=0.99$, strain $\times$ time interaction, $F=4.74, P<0.0001$. When the overall ANOVA showed a significant interaction effect, subsequent unpaired Student's $t$-tests (two-tailed) at each point in time after mAMP were performed to determine at which times the groups differed $(P<0.05)$, and these times are indicated by the asterisks. Panel inserts (dose-effect curves): the mean ( \pm S.E.M.) number of crossovers (panel I) and rears (panel $\mathbf{J}$ ) cumulated over the $160 \mathrm{~min}$ following an injection of $5,10,15$ or $30 \mathrm{mg} / \mathrm{kg}$ of cocaine. A two-way ANOVA performed on the crossover data showed significant effects of strain $(F=13.43$, $P<0.0001)$, dose $(F=39.64, P<0.0001)$ and strain $\times$ dose interaction $(F=6.91, P=0.0001)$. The asterisks indicate that LEW rats showed a greater locomotor response to 10 and $30 \mathrm{mg} / \mathrm{kg}$ cocaine, compared to F344 rats (unpaired Student's $t$ tests, $P<0.01$ ). A two-way ANOVA performed on the rearing data showed a significant effect of dose $(F=20.7, P<0.0001)$, but no significant strain $(F=1.67, P=0.20)$ or interaction effects $(F=0.84, P=0.47)$. Group $n$ values: $5 \mathrm{mg} / \mathrm{kg}$, LEW $n=20$, F344 $n=27 ; 10 \mathrm{mg} / \mathrm{kg}$, LEW $n=30$, F344 $n=30 ; 15 \mathrm{mg} / \mathrm{kg}$, LEW $n=18$, F344 $n=25 ; 30 \mathrm{mg} / \mathrm{kg}$, LEW $n=26$, F344 $n=30$. 


\section{3. $M A M P$ and $C O C$ pharmacokinetics}

Table 1 shows the brain and plasma concentrations of mAMP, AMP and COC in LEW and F344 rats. Forty min after the injection of mAMP, LEW rats had significantly higher (about 2-fold) brain and plasma concentrations of mAMP relative to F344 rats. At $\mathbf{1 2 0}$ min, the strain difference was even greater, with the concentration of mAMP being about 3 -fold higher in LEW than in F344 rats. AMP concentrations were much lower than mAMP levels, as expected. However, strain differences were present in AMP concentrations at both time points (LEW > F344). Interestingly, brain and plasma levels of AMP were actually higher at 120 min than at 40 min in LEW rats, but in F344 rats the opposite was true (i.e. a two-way ANOVA showed a significant strain $\times$ time interaction effect, $F=24.4, P$ $<0.0001$ ).

Although brain and plasma concentrations of $\mathrm{COC}$ were 2-to-3-fold higher at $40 \mathrm{~min}$ in LEW rats, relative

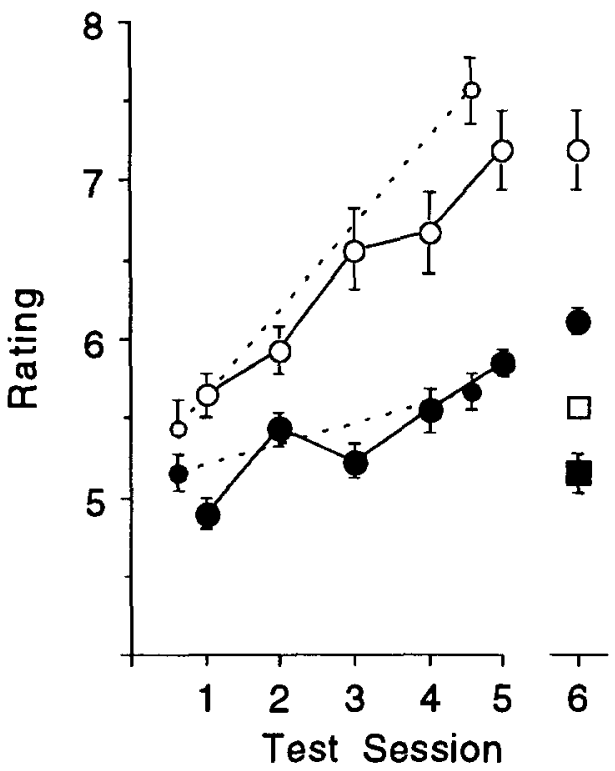

Fig. 6. The mean ( \pm S.E.M.) behavioral rating scores averaged over $60 \mathrm{~min}$ in LEW (open circles) and F344 (closed circles) rats that received a total of 6 injections of mAMP (i.e. test sessions 1-6), and in saline-pretreated LEW (open squares) and F344 (closed squares) rats that received a challenge injection of $M A M P$ during the 6th test session. Both strains showed a significant increase in rating scores across the 5 sensitization sessions (Friedman test, $P$ 's $<0.0009$ ). On the challenge session (i.e. 6th test session) mAMP-pretreated groups had significantly greater rating scores compared to their saline-pretreated controls $(U=0-0.5, P<0.0004)$. When mAMP-pretreated F344 and LEW rats were divided into two subgroups, those above and below the median score for the first test session, the first injection of mAMP did not behaviorally distinguish LEW low responders and F344 high responders $(U=8, P=0.75)$, but by the 5 th injection LEW low responders had significantly higher ratings than F344 high responders $(U=0, P=0.016$; see small symbols plotted to the left of the 1st and 5th test sessions). Group $n$ values: LEW, $n=9$ for both saline- and mAMP-pretreated groups; and F344, $n=10$ for both saline- and mAMP-pretreated groups. to F344 rats, this difference was not statistically significant because of large between subject (within strain) variation $(P=0.10-0.13$; see Table 1$)$. There was one LEW rat that had brain and plasma levels of $\operatorname{COC} 7$ to 8 times lower than the next lowest value in its group. If this animal is excluded from the analysis, then the difference between LEW and F344 rats is statistically significant $(P<0.01)$. By $80 \mathrm{~min}$ post-injection, however, there was no statistically significant strain difference in either brain or plasma levels of COC (see Table 1). These results are consistent with an earlier preliminary study, in which we quantified the concentration of $\mathrm{COC}$ in dialysate obtained from the nucleus accumbens, at 20,40 and $60 \mathrm{~min}$ following an injection of $30 \mathrm{mg} / \mathrm{kg} \mathrm{COC}$, and found that the dialysate concentration of COC was higher in LEW rats compared to $\mathrm{F} 344$ rats (at 20 min post-injection the concentration of COC in dialysate was $3.0 \pm 0.52 \mathrm{ng} / 20 \mu \mathrm{l}$ and $1.58 \pm 0.32 \mathrm{ng} / 20 \mu \mathrm{l}$ for LEW $(n=4)$ and F344 $(n=4)$ rats, respectively, $t=2.34, P=0.06$; at $40 \mathrm{~min}$ it was $5.15 \pm 1.08$ and $2.12 \pm 0.59 \mathrm{ng} / 20 \mu \mathrm{l}$, respectively, $t=$ $2.46, P=0.05$; at $60 \mathrm{~min}$ it was $3.3 \pm 0.80$ and $1.78 \pm$ $0.13 \mathrm{ng} / 20 \mu \mathrm{l}$, respectively, $t=1.88, P=0.11$ ).

\section{Discussion}

The present results extend the growing list of behavioral, biochemical $[18,37]$ and neuroendocrinological $[6,44]$ differences reported between LEW and F344 rats. First, LEW rats were more sensitive to the psychomotor activating effects of both mAMP and COC, as indicated by a shift to the left in the dose-effect curves relative to F344 rats. Secondly, LEW rats were more susceptible to mAMP sensitization. Thirdly, LEW rats showed a greater increase in extracellular DA in the ventral striatum in response to mAMP and COC, as indicated by a shift to the left in the dose-effect curves relative to F344 rats. Furthermore, strain differences in both the behavioral and neurochemical measures reported here were primarily due to an increased duration of action of MAMP and COC in LEW rats. Finally, the neurobiological basis of these strain differences is not established, but the results of Experiment 2 suggest strain differences in drug pharmacokinetics may play an important role.

\subsection{LEW/F344 differences in the behavioral effects of addictive drugs}

Although there have been a number of reports that the reinforcing effects of addictive drugs differ in LEW and F344 rats (see Introduction), there have been relatively few studies on strain differences in their psychomotor stimulant effects. George and his colleagues $[17,19]$ reported that LEW rats show greater 
locomotor activity in response to COC than F344 rats, and this effect was replicated here to the extent that LEW rats displayed greater locomotor activity following both $10 \mathrm{mg} / \mathrm{kg}$ and $30 \mathrm{mg} / \mathrm{kg}$ of COC (although compare with [28]). In contrast, George et al. [19] reported that D-amphetamine administered subcutaneously produced greater locomotor stimulation in
F344 rats than in LEW rats, whereas in the present experiment LEW rats were more responsive to the psychomotor activating effects of mAMP than F344 rats. This apparent discrepancy may be due to differences in the action of D-amphetamine vs. mAMP, or in the route of drug administration (subcutaneous vs. intraperitoneal). However, a more likely alternative
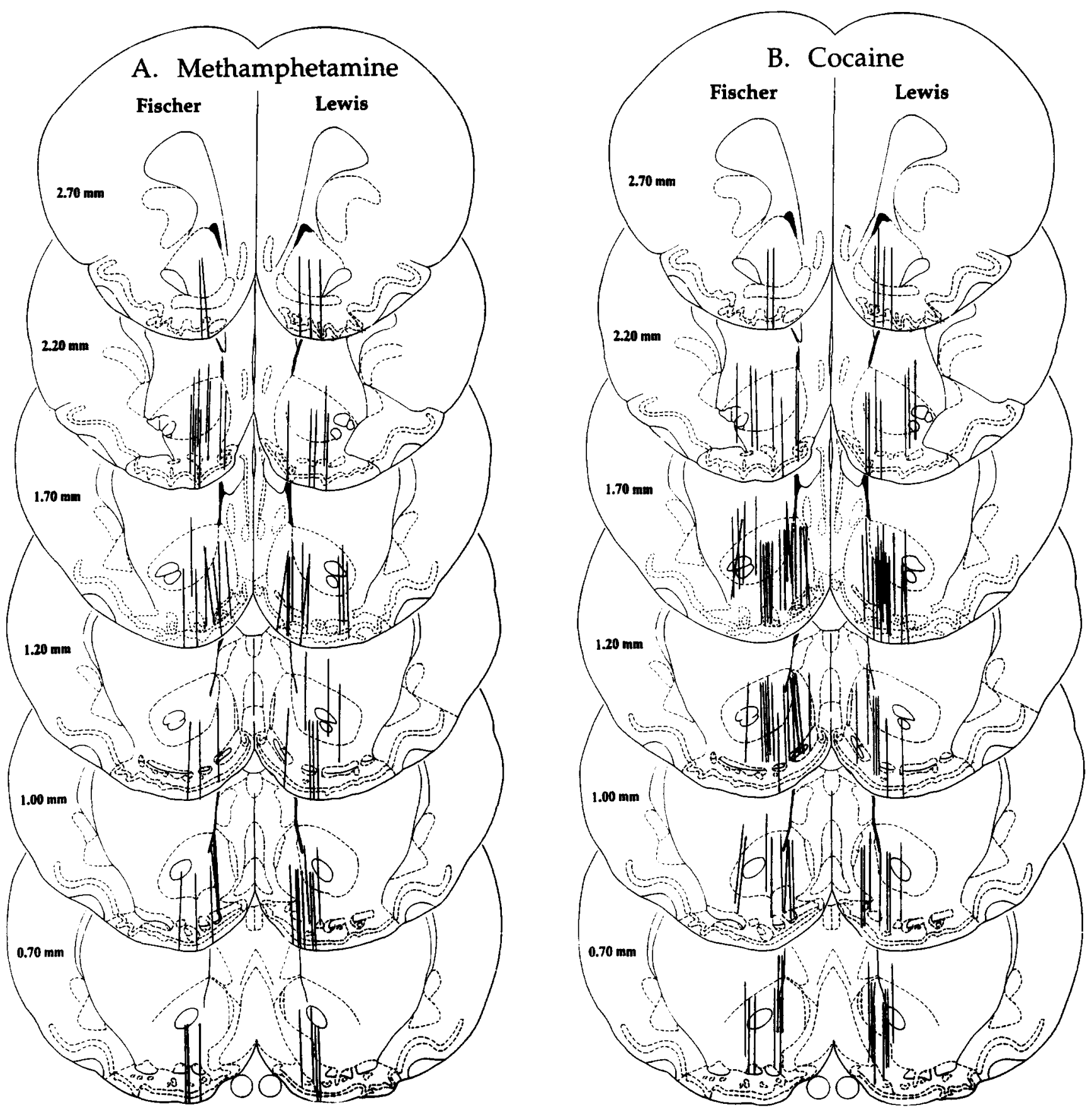

Fig. 7. Schematic representation of the location of the active surface of the dialysis probes in the ventral striatum in F344 and LEW rats. Panel A shows the location of probes ( $n=31$ for F344; 37 for LEW) for animals that received mAMP, and Panel $B$ shows the location of probes ( $n=57$ for F344 and 49 for LEW) for animals that received COC. In each case, the location of probes in F344 rats is shown in the left half of each section and in the right half of each section for LEW rats. The drawings are based on the atlas of Paxinos and Watson [39]. The number on each drawing indicates the distance anterior to bregma. 
explanation involves the way the behavioral measures were obtained and analyzed. George et al. [19] reported dose-effect curves for cumulative locomotor activity scores based on only a $60 \mathrm{~min}$ test, and from these calculated $\mathrm{ED}_{50}$ values. Although the $\mathrm{ED}_{50}$ value for D-amphetamine-induced locomotor activity was greater for LEW than for F344 rats, LEW rats also exhibited greater maximal levels of D-amphetamine-induced locomotor activity. Furthermore, George et al. [19] did not provide data on the time course of $D$ amphetamine-induced locomotor activity, and it is re-

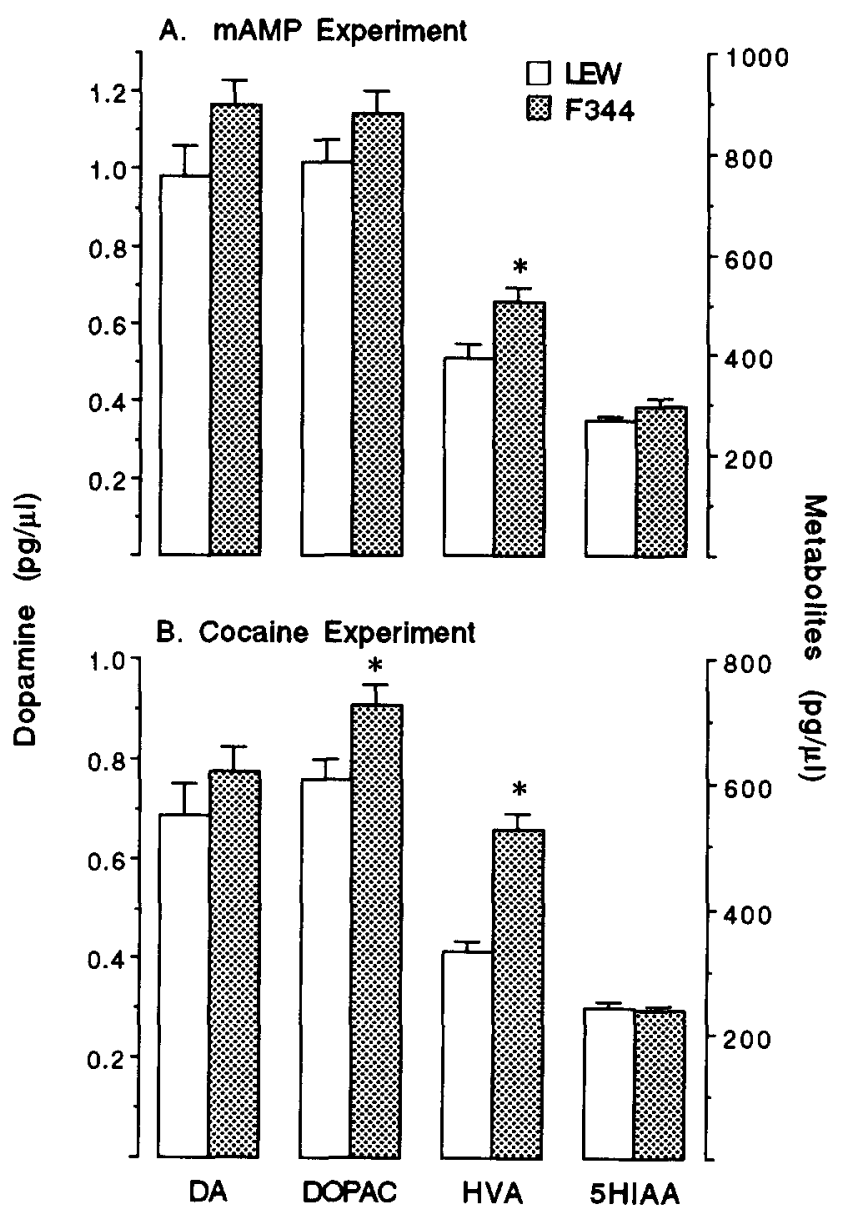

Fig. 8. The mean ( \pm S.E.M.) basal extracellular concentrations of dopamine (DA), dihydroxyphenylacetic acid (DOPAC), homovanillic acid (HVA) and 5-hydroxyindoleacetic acid (5-HIAA) measured in the ventral striatum of animals that subsequently received an injection of mAMP (Panel A) or COC (Panel B). Basal values represent the average of three $20 \mathrm{~min}$ baseline samples. There were no significant differences between LEW and F344 rats in the basal concentrations of DA (mAMP experiment, $t=1.79, P=0.077$; COC expt., $t=1.17, P=0.24$ ) or 5-HIAA (mAMP expt., $t=1.79, P=$ 0.077 ; COC expt., $t=0.28, P=0.78$ ). There were significant strain differences in the basal concentrations of DOPAC (mAMP expt., $t=1.56, P=0.124$; COC expt., $t=2.45, P=0.016)$ and HVA (mAMP expt., $t=2.81, P=0.006$; COC expt., $t=5.94, P<0.0001$ ), as indicated by the asterisks. Group $n$ values: mAMP experiment, LEW $n=37$, F344 $n=31$; Cocaine experiment, LEW $n=47$ (DA), $n=49$ (all metabolites), F344 $n=50$ (DA), $n=57$ (all metabolites).

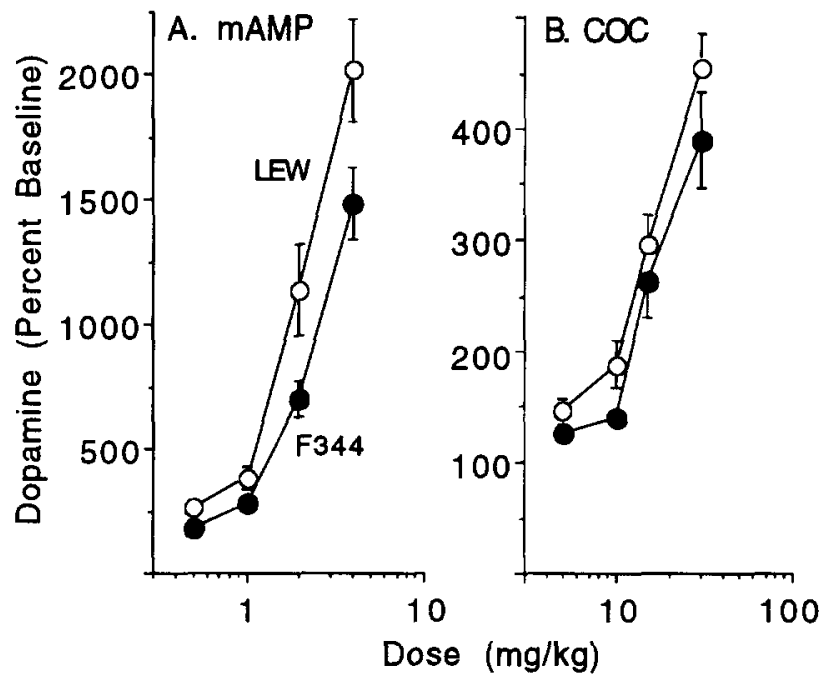

Fig. 9. The mean ( \pm S.E.M.) extracellular concentration of DA, expressed as the percent of baseline averaged over the entire 160 min period following an injection of mAMP or COC. Panel A. mAMP: A two-way ANOVA showed significant effects of strain $(F=12.56, P=0.0008)$ and dose $(F=74.9, P<0.0001)$, but no interaction effect $(F=2.03, P=0.12)$. Group $n$ values: $0.5 \mathrm{mg} / \mathrm{kg}$, LEW $n=9$, F344 $n=8 ; 1.0 \mathrm{mg} / \mathrm{kg}$, LEW $n=11$, F344 $n=8 ; 2.0$ $\mathrm{mg} / \mathrm{kg}$, LEW $n=8$, F344 $n=7 ; 4.0 \mathrm{mg} / \mathrm{kg}$, LEW $n=9$, F344 $n=8$. Panel B. COC: A two-way ANOVA showed significant effects of strain $(F=4.33, P=0.04)$ and dose $(F=45.6, P<0.0001)$, but no strain $\times$ dose interaction $(F=0.24)$. Group $n$ values: $5 \mathrm{mg} / \mathrm{kg}$, LEW $n=10$, F344 $n=10 ; 10 \mathrm{mg} / \mathrm{kg}$, LEW $n=10$, F344 $n=14 ; 15 \mathrm{mg} / \mathrm{kg}$, LEW $n=13$, F344 $n=12 ; 30 \mathrm{mg} / \mathrm{kg}$, LEW $n=14$, F344 $n=14$.

ported here LEW and F344 rats exhibited very different temporal patterns of mAMP-induced locomotor activity, rearing and stereotyped behavior. Indeed, the most salient strain difference in drug-induced stereotypy, locomotion and rearing was in the duration of the drug response, with LEW rats showing a more sustained behavioral response than F344 rats. LEW rats also are reported to show more prolonged morphineand ethylketocyclazacine-induced EEG slow-wave bursts and associated behavioral stupor than F344 rats [33,34]. Thus, the difference between George et al. [19] and the present experiment may involve the reliance on cumulative photocell counts alone as an index of the psychomotor activating effects of amphetamine. For example, a comparison of the behavioral ratings shown in Figs. 2 and 3 with the photocell counts shown in Fig. 4 illustrate the difficulty in interpreting cumulative photocell counts.

In addition to strain differences in the acute effects of mAMP and COC, LEW and F344 rats also differed in their response to repeated drug administration, with LEW rats showing greater behavioral sensitization to mAMP than F344 rats. Kosten et al. [28] recently reported a similar strain difference in cocaine sensitization. Similarly, Mayo-Michelsen and Young [32] reported that LEW rats show greater tolerance to the behavioral stupor produced by chronic morphine treat- 


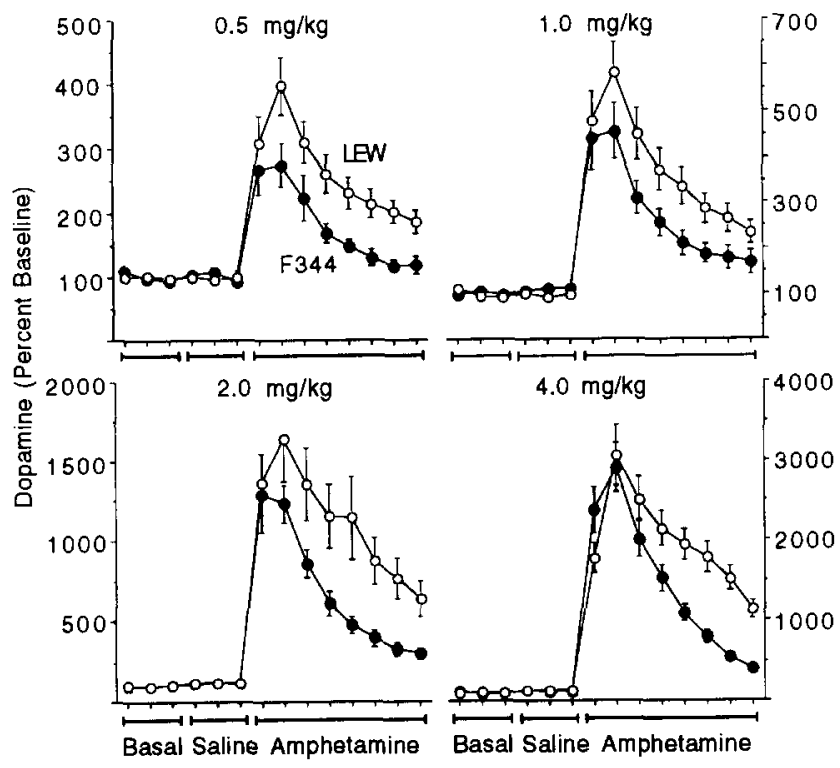

Fig. 10. The effects of $0.5,1.0,2.0$ and $4.0 \mathrm{mg} / \mathrm{kg}$ of mAMP on the mean $( \pm$ S.E.M.) extracellular concentration of DA in LEW and F344 rats. The first three $20 \mathrm{~min}$ intervals represent the basal extracellular concentration of DA, the second three intervals represent the extracellular concentration of DA following a saline injection and each subsequent $20 \mathrm{~min}$ interval was obtained following the mAMP injection. Values are expressed as a percent of the average baseline value for each animal. Two-way ANOVA's conducted over the 160 min after mAMP showed a significant effect of time for each dose ( $F$ 's range from 32 to 68 , all $P$ 's $<0.0001$ ). In addition, there were significant differences in response to mAMP between LEW and F344 rats $(0.5 \mathrm{mg} / \mathrm{kg}$, effect of strain, $F=6.35, P=0.024$, strain $\times$ time interaction, $F=0.94, P=0.49 ; 1.0 \mathrm{mg} / \mathrm{kg}$, effect of strain, $F=3.05, P=0.099$, strain $\times$ time interation, $F=0.93 ; 2.0 \mathrm{mg} / \mathrm{kg}$, effect of strain, $F=4.31, P=0.058$, strain $\times$ time interaction, $F=$ $2.14, P=0.047 ; 4.0 \mathrm{mg} / \mathrm{kg}$, effect of strain, $F=4.32, P=0.055$, strain $\times$ time interaction, $F=9.55, P<0.0001$ ). Group $n$ values are the same as in Fig. 9.

ment, as well as more pronounced behavioral symptoms during naloxone precipitated withdrawal. Although Guitart et al. [23] reported no difference between LEW and F344 rats in the severity of opiate withdrawal, the symptoms of withdrawal exhibited by the two strains were qualitatively different. In summary, the available evidence suggests that LEW rats are more sensitive than F344 rats to both the acute

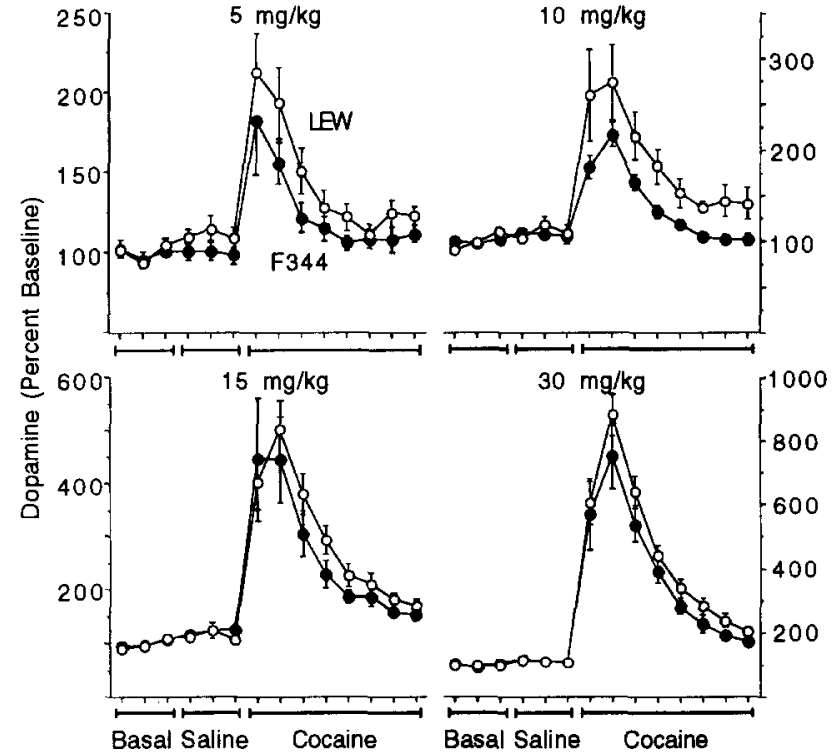

Fig. 11. The effects of $5,10,15$ and $30 \mathrm{mg} / \mathrm{kg}$ of $\mathrm{COC}$ on the mean ( \pm S.E.M.) extracellular concentration of DA in LEW and F344 rats. The first three $20 \mathrm{~min}$ intervals represent the basal extracellular concentration of DA, the second three intervals represent the extracellular concentration of DA following a saline injection and each subsequent $20 \mathrm{~min}$ interval was obtained following the $\mathrm{COC}$ injection. Values are expressed as a percent of the average baseline value for each animal. Two-way ANOVA's conducted over the $160 \mathrm{~min}$ after $\mathrm{COC}$ showed a significant effect of time for each dose $(F$ 's range from 16.8 to 67.9 , all $P$ 's $<0.0001$ ). In addition, the extracellular concentration of DA was enhanced to a greater extent in LEW rats compared to $\mathrm{F} 344$ rats following $10 \mathrm{mg} / \mathrm{kg}$ cocaine (effect of strain, $F=5.77, P=0.025$, interaction effect, $F=0.76$ ), but not following any other dose $(5.0 \mathrm{mg} / \mathrm{kg}$, strain effect, $F=2.07, P=0.17$, interaction effect, $F=0.54 ; 15 \mathrm{mg} / \mathrm{kg}$, strain effect, $F=0.6$, interaction effect, $F=0.6 ; 30 \mathrm{mg} / \mathrm{kg}$, strain effect, $F=1.51, P=0.23$, interaction effect, $F=0.4$ ). Group $n$ values are the same as in Fig. 9.

effects of a number of addictive drugs, and to changes in drug effects associated with repeated drug treatment.

\subsection{Neural correlates of the $L E W / F 344$ differences in behavioral responsivity to addictive drugs}

The neurobiological basis for the differences between LEW and F344 rats in the psychomotor-activat-

Table 1

Concentrations of methamphetamine, amphetamine or cocaine (mean \pm S.E.M.) measured in brain (ng/g tissue) and plasma (ng/ml) following an acute injection (i.p.) of methamphetamine or cocaine in LEW and F344 rats

\begin{tabular}{|c|c|c|c|c|c|c|c|}
\hline & \multirow[t]{2}{*}{ Strain } & \multicolumn{2}{|c|}{$\mathrm{mAMP}(2.0 \mathrm{mg} / \mathrm{kg})$} & \multicolumn{2}{|l|}{ Amphetamine } & \multicolumn{2}{|l|}{ Cocaine $(10 \mathrm{mg} / \mathrm{kg})$} \\
\hline & & $\overline{40 \mathrm{~min}}$ & $120 \mathrm{~min}$ & $\overline{40 \mathrm{~min}}$ & $120 \mathrm{~min}$ & $\overline{40 \mathrm{~min}}$ & $80 \mathrm{~min}$ \\
\hline \multirow{3}{*}{ Brain tissue } & & $(n=5)$ & $(n=5)$ & $(n=5)$ & $(n=5)$ & $(n=5)$ & $(n=5)$ \\
\hline & LEW & $1759.6 \pm 151.6$ * & $601.6 \pm 21.0^{* *}$ & $318.0 \pm 35.4^{*}$ & $435.0 \pm 15.5^{* *}$ & $522.8 \pm 119.6^{* * *}$ & $80.0 \pm 21.0$ \\
\hline & F344 & $948.4 \pm 110.8$ & $199.2 \pm 15.4$ & $197.1 \pm 14.2$ & $106.8 \pm 7.8$ & $285.0 \pm 74.7$ & $61.6 \pm 10.3$ \\
\hline \multirow[t]{2}{*}{ Plasma } & LEW & $148.0 \pm 12.3^{*}$ & $68.9 \pm 5.0^{* *}$ & $37.5 \pm 3.7^{*}$ & $53.2 \pm 3.7^{* *}$ & $251.5 \pm 89.7^{* * *}$ & $44.6 \pm 14.0$ \\
\hline & F344 & $95.2 \pm 8.3$ & $23.7 \pm 2.8$ & $22.9 \pm 1.5$ & $15.5 \pm 2.6$ & $88.2 \pm 26.2$ & $27.8 \pm 5.1$ \\
\hline
\end{tabular}

LEW differs from F344- ${ }^{*} P<0.01,{ }^{* *} P<0.0001$ (two-tailed $t$-test); ${ }^{* * *} P<0.01$ if one rat excluded (see text). 
ing and reinforcing effects of addictive drugs is not known, but we hypothesized that strain differences in the ability of these drugs to elevate the extracellular concentration of DA in the ventral striatum may play some role. Consistent with this, both mAMP and COC were found to elevate the extracellular concentration of DA in the ventral striatum to a greater extent in LEW rats compared to F344 rats. Furthermore, the strain difference in mAMP-induced DA release was due largely to a difference in the duration of the response. Thus, strain differences in behavioral responsivity to mAMP and in mAMP-induced DA release were both largely characterized by differences in the duration of the response, with LEW rats showing a more sustained response than F344 rats. Similarly, delta-9-tetrahydrocannabinol produces a greater increase in extracellular DA in the nucleus accumbens of LEW rats, compared to Sprague-Dawley rats [8].

Although both mAMP and COC produced a greater increase in the extracellular concentration of DA in LEW rats, compared to F344 rats, there were some differences between the two drugs. The strain difference in the COC-induced elevation in extracellular DA was smaller in comparison to that seen following mAMP, and also was not specifically associated with differences in the duration of the response. These may be due to differences in the mechanisms of action of mAMP vs. COC.

In contrast to the findings reported here for $\mathrm{COC}$, there have been two preliminary reports that acute administration of COC enhances the extracellular concentration of DA to a greater extent in F344 rats compared to LEW rats $[46,50]$. The reason for this discrepancy is not clear. However, the results may be influenced by how the extracellular concentration of DA is expressed following drug administration. In the present study, the increase in extracellular DA is reporter as a percent of baseline. If these same data are analyzed in terms of absolute values (data not presented), there is no significant difference between LEW and F344 rats at any dose of COC tested. However, this still does not explain why in these other studies COC produced a greater increase in extracellular DA in F344 rats compared to LEW rats. Given that environmental factors seem to play a large role in producing individual variability within the strains, perhaps differences in the environmental conditions between the present experiment and the previous experiments are important for these strain differences. Finally, it is possible that differences in probe placements and other procedural differences might acccount for the discrepant findings.

It is important to note that the strain differences in stimulated DA activity were not associated with strain differences in basal levels of DA. However, basal levels of the DA metabolites, DOPAC and HVA, were higher in F344 rats. Basal metabolites in dialysate are thought to largely originate from the intraneuronal metabolism of DA, independent of DA release [29,53], and therefore, may reflect the rate of DA synthesis. If this is true, then one might expect to see strain differences in tyrosine hydroxylase activity, the rate-limiting enzyme for DA synthesis. Indeed, LEW rats have higher levels of tyrosine hydroxylase in the VTA [2], and lower levels in the nucleus accumbens [2], striatum and midbrain [43], relative to F344 rats. The extent to which LEW/F344 differences in tyrosine hydroxylase are related to the differences in DA metabolites seen here is unknown.

\subsection{Pharmacokinetics}

Although many researchers have acknowledged the possibility that some of the differences between LEW and F344 rats in drug response may be due to pharmacokinetics, there have been very few experiments designed to test this hypothesis. We are not aware of any previous studies on amphetamine pharmacokinetics in LEW vs. F344 rats, but in the present study plasma and brain levels of mAMP were two to three-fold higher in LEW rats compared to $\mathrm{F} 344$ rats following $2.0 \mathrm{mg} / \mathrm{kg}$ of mAMP (i.p.). Furthermore, the magnitude of the strain difference in mAMP levels was larger at $2 \mathrm{~h}$ than at $40 \mathrm{~min}$ following mAMP administration, which is also when the behavioral and neurochemical differences were greatest. We are aware of only one previous study on COC pharmacokinetics in LEW and F344 rats [22]. Guitart et al. [22] measured blood levels of $\mathrm{COC}$ at 15,30 and $60 \mathrm{~min}$ after an injection of 15 $\mathrm{mg} / \mathrm{kg}$ COC (i.p.) and found no differences between LEW and F344 rats. In contrast, we found that the levels of COC in plasma and in brain were higher in LEW rats compared to F344 rats 40 min following an injection of $10 \mathrm{mg} / \mathrm{kg} \mathrm{COC} \mathrm{(although} \mathrm{there} \mathrm{was} \mathrm{a} \mathrm{great}$ deal of individual variation). Studies on morphine pharmacokinetics in LEW and F344 rats also are not entirely consistent [21,22]. Gosnell and Krahn [21] reported that the brain concentration of morphine following a $3 \mathrm{mg} / \mathrm{kg}$ s.c. injection of morphine was lower in LEW rats $30 \mathrm{~min}$ after the injection, but no different from F344 rats $3 \mathrm{~h}$ after the injection, whereas serum levels of morphine did not differ at $30 \mathrm{~min}$, but were higher in LEW rats at $3 \mathrm{~h}$. In contrast, Guitart et al. [22] reported that plasma levels of morphine did not differ between these two strains at 15,30 and $60 \mathrm{~min}$ after a subcutaneous injection of $4 \mathrm{mg} / \mathrm{kg}$ morphine sulfate.

The reason(s) for the apparent differences between LEW and F344 rats in COC and MAMP pharmacokinetics is unknown, and cannot be determined from this study. Strain differences in the rate of drug absorption, metabolism, distribution or elimination could be in- 
volved. Indeed, differences between LEW and F344 rats have been reported in hepatic catechol- $O$-methyl transferase (COMT) activity [51], and serum dopamine$\beta$-hydroxylase activity [45]. Whatever the mechanism, given the present interest in using LEW and F344 rats to study the neurobiology of addiction, the preliminary results reported here suggest more comprehensive studies on strain differences in drug pharmacokinetics are warranted.

\subsection{Conclusions}

In summary, it was found that both COC and mAMP produce greater psychomotor activation in LEW compared to F344 rats, and this was associated with differences in the ability of these drugs to enhance the extracellular concentration of DA in the ventral striatum. These results extend the growing list of behavioral and biochemical differences in the effects of addictive drugs reported between these two strains. However, there were also strain differences in the plasma and brain concentrations of MAMP and COC following systemic administration, suggesting strain differences in drug pharmacokinetics may contribute to these behavioral and neurochemical effects. If confirmed this would have important implications for the notion that LEW rats may be especially vulnerable to addictive drugs.

\section{Acknowledgements}

We thank Erin Wolfe and Steve Simmerville for their assistance in conducting some of the experiments, and Drs. R. Foltz and D. Moody at the Center for Human Toxicology, University of Utah for performing the drug analyses (NIDA Contract No. DA-2-7314). This research was supported by Grant 04294 from the National Institute on Drug Abuse to T.E.R.

\section{References}

[1] Beatty, W.W., Dodge, A.M. and Traylor, K.L., Stereotyped behavior elicited by amphetamine in the rat: influences of the testes, Pharmacol. Biochem. Behav., 16 (1982) 565-568.

[2] Beitner-Johnson, D., Guitart, X. and Nestler, E.J., Dopaminergic brain reward regions of Lewis and Fischer rats display different levels of tyrosine hydroxylase and other morphine- and cocaine-regulated phosphoproteins, Brain Res., 561 (1991) 14750.

[3] Beitner-Johnson, D., Guitart, X. and Nestler, E.J., Common intracellular actions of chronic morphine and cocaine in dopaminergic brain reward regions, Ann. NY Acad. Sci., 654 (1992) 70-87.

[4] Beitner-Johnson, D., Guitart, X. and Nestler, E.J., Glial fibrillary acidic protein and the mesolimbic dopamine system: regulation by chronic morphine and Lewis-Fischer strain differences in the rat ventral tegmental area, J. Neurochem., 61 (1993) $1766-73$.

[5] Brogan, W.C., Kemp, P.M., Bost, R.O., Glamann, D.B., Lange, R.A. and Hillis, L.D., Collection and handling of clinical blood samples to assure the accurate measurement of cocaine concentration, J. Anal. Toxicol., 16 (1992) 152-154.

[6] Calogero, A.E., Sternberg, E.M., Bagdy, G., Smith, C., Bernardini, R., Aksentijevich, S., Wilder, R.L., Gold, P.W. and Chrousos, G.P., Neurotransmitter-induced hypothalamic-pituitary-adrenal axis responsiveness is defective in inflammatory disease-susceptible Lewis rats: in vivo and in vitro studies suggesting globally defective hypothalamic secretion of corticotropin-releasing hormone, Neuroendocrinology, 55 (1992) 600-608.

[7] Camp, D.M. and Robinson, T.E., Susceptibility to sensitization. I. Sex differences in the enduring effects of chronic Damphetamine treatment on locomotion, stereotyped behavior and brain monoamines, Behav. Brain Res., 30 (1988) 55-68.

[8] Chen, J.P., Paredes, W., Lowinson, J.H. and Gardner, E.L., Strain-specific facilitation of dopamine efflux by delta 9-tetrahydrocannabinol in the nucleus accumbens of rat: an in vivo microdialysis study, Neurosci. Lett., 129 (1991) 136-80.

[9] Deminiere, J.M., Piazza, P.V., Le Moal, M. and Simon, H., Experimental approach to individual vulnerability to psychostimulant addiction, Neurosci. Biobehav. Rev., 13 (1989) 141-147.

[10] Di Chiara, G. and Imperato, A., Drugs abused by humans preferentially increase synaptic dopamine concentrations in the mesolimbic system of freely moving rats, Proc. Natl. Acad. Sci. USA, 85 (1988) 5274-8.

[11] Ellinwood Jr., E.H. and Balster, R.L., Rating the behavioral effects of amphetamine, Eur. J. Pharmacol., 28 (1974) 35-41.

[12] Gardner, E.L. and Lowinson, J.H., Marijuana's interaction with brain reward systems: Update 1991, Pharmacol. Biochem. Behav, 40 (1991) 571-580.

[13] Gardner, E.L., Paredes, W., Smith, D., Seeger, T., Donner, A., Milling, C., Cohen, D. and Morrison, D., Strain-specific sensitization of brain stimulation reward by delta 9-tetrahydrocannabinol in laboratory rats, Psychopharmacology (Berlin), 96 (Suppl) (1988) 365.

[14] George, F.R., Genetic and environmental factors in ethanol self-administration, Pharmacol. Biochem. Behav., 27 (1987) 37984.

[15] George, F.R., Genetic approaches to studying drug abuse: correlates of drug self-administration, Alcohol, 7 (1990) 207-11.

[16] George, F.R., Genetic models in the study of alcoholism and substance abuse mechanisms, Prog. Neuropsychopharmacol. Biol. Psychiatry, 17 (1993) 345-61.

[17] George, F.R. and Goldberg, S.R., Genetic differences in responses to cocaine, Nida Res. Monogr., 88 (1988) 239-49.

[18] George, F.R. and Goldberg, S.R., Genetic approaches to the analysis of addiction processes, Trends Pharmacol. Sci., 10 (1989) $78-83$.

[19] George, F.R., Porrino, L.J., Ritz, M.C. and Goldgerg, S.R., Inbred rat strain comparisons indicate different sites of action for cocaine and amphetamine locomotor stimulant effects, Psychopharmacology, 104 (1991) 457-462.

[20] Glick, S.D. and Hinds, P.A., Differences in amphetamine and morphine sensitivity in lateralized and non-lateralized rats: locomotor activity and drug self- administration, Eur. J. Pharmacol, 118 (1985) 239-44.

[21] Gosnell, B.A. and Krahn, D.D., Morphine-induced feeding: a comparison of the Lewis and Fischer 344 inbred rat strains, Pharmacol. Biochem. Behav., 44 (1993) 919-24.

[22] Guitart, X., Beitner-Johnson, D., Marby, D.W., Kosten, T.A. and Nestler, E.J., Fischer and Lewis rat strains differ in basal levels of neurofilament proteins and their regulation by chronic morphine in the mesolimbic dopamine system, Synapse, 12 (1992) 242-53. 
[23] Guitart, X., Kogan, J.H., Berhow, M., Terwilliger, R.Z., Aghajanian, G.K. and Nestler, E.J., Lewis and Fischer rat strains display differences in biochemical, electrophysiological and behavioral parameters: studies in the nucleus accumbens and locus coeruleus of drug naive and morphine-treated animals, Brain Res., 611 (1993) 7-17.

[24] Heffner, T.G., Hartman, J.A. and Seiden, L.S., A rapid method for the regional dissection of the rat brain, Pharmacol. Biochem. Behav., 13 (1980) 453-56.

[25] Hurd, Y.L. and Ungerstedt, U., Cocaine: an in vivo microdialysis evaluation of its acute action on dopamine transmission in rat striatum, Synapse, 3 (1989) 48-54.

[26] Kalivas, P.W. and Duffy, P., Effect of acute and daily cocaine treatment on extracellular dopamine in the nucleus accumbens, Synapse, 5 (1990) 48-58.

[27] Kato, R., Sex-related differences in drug metabolism, Drug Metabol. Rev., 3 (1974) 1-32.

[28] Kosten, T.A., Miserendino, M.J.D., Chi, S. and Nestler, E.J., Fischer and Lewis rat strains show differential cocaine effects on conditioned place preference and behavioral sensitization but not in locomotor activity or conditioned taste aversion, $J$. Pharmacol. Exp. Ther., 269 (1994) 137-144.

[29] Kuczenski, R. and Segal, D., Concomitant characterization of behavioral and striatal neurotransmitter response to amphetamine using in vivo microdialysis, J. Neurosci., 9 (1989) 2051-2065.

[30] Li, T. and Lumeng, L., Alcohol preference and voluntary alcohol intakes of inbred rat strains and the National Institutes of Health heterogeneous stock of rats, Alcoholism: Clin. Exp. Res., 8 (1984) 485-486.

[31] Luedtke, R.R., Artymyshyn, R.P., Monks, B.R. and Molinoff, P.B., Comparison of the expression, transcription and genomic organization of D2 dopamine receptors in outbred and inbred strains of rat, Brain Res., 584 (1992) 45-54.

[32] Mayo-Michelson, L. and Young, G.A., Effects of chronic morphine administration and naloxone on EEG, EEG power spectra, and associated behavior in two inbred rat strains, Pharmacol. Biochem. Behav., 42 (1992) 815-21.

[33] Mayo-Michelson, L. and Young, G.A., EEG, EEG power spectral, and behavioral differences in response to acute ethylketocyclazocine administration in two inbred rat strains, Brain Res. Bull., 31 (1993) 345-51.

[34] Mayo-Michelson, L. and Young, G.A., Genetic profiles of morphine-induced EEG, EEG power spectra, and behavior in two inbred rat strains, Brain Res. Bull., 30 (1993) 79-84.

[35] Moghaddam, B. and Bunney, B.S., Ionic composition of microdialysis perfusing solution alters the pharmacological responsiveness and basal outflow of striatal dopamine, J. Neurochem., 53 (1989) 652-4.

[36] Morrison, D.F., Multivariate statistical methods, McGraw-Hill, New York, 1967.

[37] Nestler, E.J., Molecular mechanisms of drug addiction, J. Neurosci., 12 (1992) 2439-2450.

[38] Nomikos, G.G., Damsma, G., Wenkstern, D. and Fibiger, H.C., In vivo characterization of locally applied dopamine uptake inhibitors by striatal microdialysis, Synapse, 6 (1990) 106-112.
[39] Paxinos, G. and Watson, C., The Rat Brain in Stereotaxic Coordinates, Raven Press, New York, 1986.

[40] Piazza, P.V., Deminière, J.M., Le Moal, M. and Simon, H., Factors that predict individual vulnerability to amphetamine self-administration, Science, 245 (1989) 1511-3.

[41] Robinson, T.E. and Camp, D.M., The feasibility of repeated microdialysis for within-subjects design experiments: studies on the mesostriatal dopamine system. In T.E. Robinson and J.B. Justice Jr. (Eds.), Microdialysis in the Neurosciences, Elsevier, Amsterdam, 1991, pp. 189-234.

[42] Seale, T.W., Genetic differences in response to cocaine and stimulant drugs. In J.C. Crabbe and R. Adron (Eds.), The Genetic Basis of Alcohol and Drug Actions, Plenum Press, New York, 1991, pp. 279-321.

[43] Segal, D.S., Kuczenski, R.T. and Mandell, A.J., Strain differences in behavior and brain tyrosine hydroxylase activity, Behav. Biol., 7 (1972) 75-81.

[44] Sternberg, E.M., Glowa, J.R., Smith, M.A., Calogero, A.E., Listwak, S.J., Aksentijevich, S., Chrousos, G.P., Wilder, R.L. and Gold, P.W., Corticotropin releasing hormone related behavioral and neuroendocrine responses to stress in Lewis and Fischer rats, Brain Res., 570 (1992) 54-60.

[45] Stolk, J.M., Hurst, J.H., Van Riper, D.A. and Harris, P.Q., Genetic analysis of serum dopamine- $\beta$-hydroxylase activity in rats, Mol. Pharmacol., 16 (1979) 922-31.

[46] Strecker, R.E., Eberle, W.F. and Ashby, C.R., Cocaine-induced changes in extracellular dopamine levels in the nucleus accumbens of Fischer and Lewis rats, Soc. Neurosci. Abstr., 19 (1993) 1825 .

[47] Suzuki, T., George, F.R. and Meisch, R.A., Differential establishment and maintenance of oral ethanol reinforced behavior in Lewis and Fischer 344 inbred rat strains, J. Pharmacol. Exp. Ther., 245 (1988) 164-70.

[48] Suzuki, T., George, F.R. and Meisch, R.A., Etonitazene delivered orally serves as a reinforcer for Lewis but not Fischer 344 rats, Pharmacol. Biochem. Behav., 42 (1992) 579-86.

[49] Suzuki, T., Otani, K., Koike, Y. and Misawa, M., Genetic differences in preferences for morphine and codeine in Lewis and Fischer 344 inbred rat strains, Jpn J. Pharmacol., 47 (1988) 425-31.

[50] Terwilliger, R.Z., Bradberry, C., Guitart, X., Beitner-Johnson, D., Marby, D., Kosten, T.A., Roth, R.H. and Nestler, E.J., Lewis and Fischer 344 rats and drug addiction: behavioral and biochemical correlates, Soc. Neurosci. Abstr., 17 (1991) 823.

[51] Weinshilboum, R. and Raymond, F., Variations in catechol-Omethyltransferase activity in inbred strains of rats, Neuropharmacology, 16 (1977) 703-6.

[52] Wise, R.A. and Bozarth, M.A., A psychomotor stimulant theory of addiction, Psychol. Rev., 94 (1987) 469-92.

[53] Zetterström, T., Sharp, T., Collin, A.K. and Ungerstedt, U., In vivo measurement of extracellular dopamine and DOPAC in rat striatum after various dopamine-releasing drugs; implications for the origin of extracellular DOPAC., Eur. J. Pharmacol., 148 (1988) $327-34$ 